Article

\title{
Phosphoproteins Involved in the Inhibition of Apoptosis and in Cell Survival in the Leiomyoma
}

\author{
Blendi Ura ${ }^{1, *}$, Lorenzo Monasta ${ }^{1}\left(\mathbb{D}\right.$, Giorgio Arrigoni $^{2,3}{ }^{(\mathbb{D}}$, Ilaria Battisti ${ }^{3}$, Danilo Licastro ${ }^{4}$, \\ Giovanni Di Lorenzo ${ }^{1}$, Federico Romano ${ }^{1}{ }^{(\mathbb{D}}$, Michelangelo Aloisio ${ }^{1}{ }^{(D}$, Isabel Peterlunger ${ }^{1}$, \\ Guglielmo Stabile ${ }^{1}$, Federica Scrimin ${ }^{1}$ and Giuseppe Ricci ${ }^{1,5}$ \\ 1 Institute for Maternal and Child Health-IRCCS “Burlo Garofolo”, 65/1 Via dell'Istria, I-34137 Trieste, Italy; \\ lorenzo.monasta@burlo.trieste.it (L.M.); giovanni.dilorenzo@burlo.trieste.it (G.D.L.); \\ federico.romano@burlo.trieste.it (F.R.); michelangeloaloisio@libero.it (M.A.); \\ isabel.peterlunger@libero.it (I.P.); guglielmost@gmail.com (G.S.); federica.scrimin@burlo.trieste.it (F.S.); \\ giuseppe.ricci@burlo.trieste.it (G.R.) \\ 2 Department of Biomedical Sciences, University of Padova, 35121 Padova, Italy; giorgio.arrigoni@unipd.it \\ 3 Proteomics Center, University of Padova and Azienda Ospedaliera di Padova, I-35129 Padova, Italy; \\ ilaria.battisti@studenti.unipd.it \\ 4 CBM scrl, Area Science Park, I-34149 Trieste, Italy; danilo.licasto@cbm.fvg.it \\ 5 Department of Medical, Surgery and Health Sciences, University of Trieste, I-34149 Trieste, Italy \\ * Correspondence: blendi.ura2006@libero.it; Tel.: +39-040-3785863
}

Received: 3 April 2019; Accepted: 13 May 2019; Published: 16 May 2019

\begin{abstract}
Uterine leiomyomas are benign smooth muscle cell tumors originating from the myometrium. In this study we focus on leiomyoma and normal myometrium phosphoproteome, to identify differentially phosphorylated proteins involved in tumorigenic signaling pathways, and in anti-apoptotic processes and cell survival. We obtained paired tissue samples of seven leiomyomas and adjacent myometria and analyzed the phosphoproteome by two-dimensional gel electrophoresis (2-DE) combined with immobilized metal affinity chromatography (IMAC) and Pro-Q Diamond phosphoprotein gel stain. We used mass spectrometry for protein identification and Western blotting for 2-DE data validation. Quantities of 33 proteins enriched by the IMAC approach were significantly different in the leiomyoma if compared to the myometrium. Bioinformatic analysis revealed ten tumorigenic signaling pathways and four phosphoproteins involved in both the inhibition of apoptosis and cell survival. Our study highlights the involvement of the phosphoproteome in leiomyoma growth. Further studies are needed to understand the role of phosphorylation in leiomyoma. Our data shed light on mechanisms that still need to be ascertained, but could open the path to a new class of drugs that not only can block the growth, but could also lead to a significant reduction in tumor size.
\end{abstract}

Keywords: phosphoproteomics; leiomyoma; 2-DE; myometrium; mass spectrometry

\section{Introduction}

Uterine leiomyomas are benign smooth muscle cell tumors originating from the myometrium. These tumors can occur in $70-80 \%$ of women and are the first gynecological reason why women undergo hysterectomy [1]. They are responsible for severe health problems, including pain, infertility, repetitive pregnancy loss and heavy uterine bleeding [2]. To date, little is known about the pathogenesis of this tumor, and this leads to the lack of a valid medical treatment. Leiomyomas are characterized by a hyperproduction of extracellular matrix (ECM) [3], and by high interstitial fluid pressure ( $\mathrm{P}_{\text {if }}$ [ [4].

Phosphorylation occurs in target amino acids, usually in serine, threonine, or tyrosine residues [5]. It is known that phosphorylation is the most relevant post-translational protein modification [6] and that altered phosphorylation in cellular pathways is strongly associated with tumors [7]. 
Hermon TL et al. showed that estrogen receptor $\alpha(E R \alpha)$ is significantly more phosphorylated on serine in the leiomyoma, if compared to the myometrium, and is regulated by ERK1/2 leading to leiomyoma development [8,9]. Over-phosphorylation of receptor tyrosine kinases (RTKs), that regulate several cellular processes in tumors, like differentiation and proliferation, is associated with cell proliferation in the leiomyoma [10]. Signals of other cell membrane receptors, like transforming growth factor beta (TGF- $\beta$ ), activin, myostatin are transmitted to the nucleus through Smads proteins. The intracellular effectors of TGF- $\beta$ signaling lead to the activation of Smad proteins by phosphorylation. These proteins are transferred to the nucleus, modulating gene expression [11]. In the leiomyoma, Smad2/3 is over phosphorylated if compared to the myometrium, and the use of GnRH-agonist treatment induces a reduction in phosphorylation of this protein [12]. Several studies have shown the dysregulation of the PI3K/Akt/mTOR pathway. Indeed, they find an increase in cyclin $\mathrm{D}_{2}$ and glycogen synthase kinase 3 (GSK3) and a decrease of phosphatidylinositol 3,4,5-trisphosphate 3-phosphatase (PTEN) leading to leiomyoma development [13]. There is evidence that the Ras/Raf/MEK/ERK pathway is dysregulated in the leiomyoma. Several studies have shown that different kinases, such as ERK and RTK, are altered in this pathway and this may be related to the disease $[14,15]$.

For the reasons described above, the identification of changes in protein phosphorylation levels in the leiomyoma may be useful for the understanding of the tumor physiopathology. Several proteomic studies have been conducted and studies have identified proteins involved in leiomyoma pathology $[16,17]$.

The objective of our study was to create a phosphoproteomic profile by using Pro-Q Diamond and immobilized metal affinity chromatography (IMAC) of leiomyoma and myometrial tissues, for the identification of differentially phosphorylated proteins involved in tumorigenic signaling pathways and in anti-apoptotic and cell survival processes.

\section{Materials and Methods}

\subsection{General}

Tissues samples were obtained from seven premenopausal patients who underwent hysterectomy for symptomatic uterine leiomyomas. All procedures conformed to the Declaration of Helsinki and were approved by the Review Board of the Institute for Maternal and Child Health-IRCCS “Burlo Garofolo" (Trieste, Italy). All subjects involved signed a written informed consent. The median age of patients was 45 years, with a minimum of 36 and a maximum of 48 years.

Oncologic patients; Human immunodeficiency virus (HIV), Hepatitis B virus (HBV), Hepatitis $\mathrm{C}$ virus (HCV) seropositive patients; and patients with adenomyosis were excluded from the study. The patients had not received hormonal therapy in the three months before surgery.

\subsection{Tissue Samples}

Two samples were collected from each patient: one from the central area of the leiomyoma and one from the unaffected myometrium situated more than $2 \mathrm{~cm}$ away from the leiomyoma capsule. All leiomyomas were confirmed histologically as benign ordinary leiomyomas. All leiomyomas were subserosal/intramural with dimensions ranging from 4 to $6 \mathrm{~cm}$. Samples were stored at $-80{ }^{\circ} \mathrm{C}$ until proteomic analysis was performed.

\subsection{Phosphoprotein Isolation, Pro-Q Diamond and 2-DE}

One hundred mg of myometrium and leiomyoma tissue from seven patients were used for phosphoprotein isolation by Phosphoprotein Enrichment Kit (Pierce). Tissues were homogenized in (1\% NP-40, 50 mM Tris-HCl (pH 8.0), NaCl 150 mM) with Phosphatase Inhibitor Cocktail Set II 1× (Millipore, Burlington, VT, USA) and $2 \mathrm{mM}$ phenylmethylsulfonyl fluoride (PMSF), $1 \mathrm{mM}$ benzamidine. The concentration of the supernatant was determined by Bradford. Tissue homogenates were then 
diluted to $0.4 \mathrm{mg} / \mathrm{ml}$ in lysis buffer provided by the Phosphoprotein Enrichment Kit. Six $\mathrm{ml}$ of final samples were used for isolation of the phosphoprotein according to the manufacturer's instructions.

2-DE was performed as previously described [18]. For 2-DE analysis, $250 \mu \mathrm{g}$ of proteins from each sample (obtained after phosphoproteins enrichment, as specified above) were denatured in $300 \mu \mathrm{l}$ of dissolution buffer (7 M urea, $2 \mathrm{M}$ thiourea, 4\% 3-((3-cholamidopropyl)dimethylammonio)1-propanesulfonate, $40 \mathrm{mM}$ Tris, $65 \mathrm{mM}$ dithiothreitol (DTT), and 0.24\% Bio-Lyte 3/10 (Bio-Rad Laboratories, Inc., Hercules, CA, USA) and a trace of bromophenol blue. ReadyStrip ${ }^{\mathrm{TM}} \mathrm{pH} 4-7$ 18-cm immobilized pH gradient (IPG) strips (Bio-Rad Laboratories, Inc., Hercules, CA, USA) were rehydrated in a dissolution buffer at $50 \mathrm{~V}$ for $12 \mathrm{~h}$ at $20^{\circ} \mathrm{C}$, and isoelectric focusing (IEF) was performed in a PROTEAN IEF Cell (Bio-Rad Laboratories, Inc., Hercules, CA, USA). After the IEF, serial incubations were performed: first, the IPG strips were equilibrated for $20 \mathrm{~min}$ in an equilibration buffer (6 M urea, $2 \%$ SDS, $50 \mathrm{mM}$ Tris-HCl (pH 8.8), 30\% glycerol and 1\% DTT) and then in another equilibration buffer containing $4 \%$ iodoacetamide instead of DTT. For the second dimension, the equilibrated IPG strips were transferred to a $12 \%$ polyacrylamide gel.

After electrophoresis, gels were fixed in $40 \%$ methanol and $10 \%$ acetic acid for $1 \mathrm{~h}$, and then stained for 16h with SYPRO Ruby. 2-DE gels were scanned with a Molecular Imager PharosFX System. Double experimental replicates were performed per sample.

For the experiment with Pro-Q Diamond dye (Thermo Life Technologies, Waltham, MA, USA), seven patients (the same patients used for phosphoproteome enrichment) were used. One thousand $\mu \mathrm{g}$ of proteins were used for 2-DE as described above. Gels were first stained with Pro-Q Diamond dye according to manufacturer's instructions, washed with water, and scanned with Pharos FX Plus Molecular Imager (Bio-Rad) to visualize the phosphoproteome. Gels were stained for $16 \mathrm{~h}$ with SYPRO Ruby to reveal the total proteome. Double experimental replicates were performed per each sample. For all gels, molecular weights were determined by comparison with Precision Plus Protein Pre-stained Standards (Bio-Rad Laboratories, Inc., Hercules, CA, USA), covering a range from 10 to $250 \mathrm{kDa}$ and analyzed using the Proteomweaver 4.0 software (both from Bio-Rad Laboratories, Inc., Hercules, CA, USA).

\subsection{Quantification of Spot Levels}

2-DE image analysis was performed using the Proteomweaver 4.0 software. The analysis process was carried out by matching all gels from seven myometria and seven leiomyomas. The Proteomweaver 4.0 algorithm matched all of the gels to find quantitative differences. Differences were considered significant when the ratio of the mean percentage relative volume $(\% V)(\% V=V($ single spot $) / V($ total spot)) was \pm 1.5 -fold and satisfied the non-parametric Wilcoxon test $(P<0.05)$. For Pro-Q Diamond gel stain, the ratios of relative protein abundance values between the myometrium and the leiomyoma were calculated. Ratios $\geq 1.5$ and $\leq 0.6$ were considered as significantly different. The relative protein abundance of phosphoproteins (P) was calculated in the Pro-Q Diamond images and in the SYPRO Ruby images, as previously described by Wang and colleagues [19].

\subsection{Trypsin Digestion and MS Analysis}

Spots from 2-DE were digested and analyzed by mass spectrometry, as described by Ura et al. [20].

After excision from 2-DE gels, the spots were washed four times with $50 \mathrm{mM} \mathrm{NH}_{4} \mathrm{HCO}_{3}$ and acetonitrile (ACN; Sigma-Aldrich, St. Louis, MO, USA) alternatively, and dried under vacuum in a SpeedVac system. For gel spot digestion, three microliters of $12.5 \mathrm{ng} / \mu \mathrm{L}$ sequencing grade modified trypsin (Promega, Madison, WI, USA) in $50 \mathrm{mM} \mathrm{NH}_{4} \mathrm{HCO}_{3}$ were added, and samples were digested overnight at $37^{\circ} \mathrm{C}$. Peptides extraction was made by three changes of $50 \%$ ACN $/ 0.1 \%$ formic acid (FA; Fluka, Ammerbuch, Germany), peptide mixtures were dried under vacuum and stored at $-20{ }^{\circ} \mathrm{C}$, until mass spectrometry (MS) analysis was performed.

Samples were dissolved in $10 \mu \mathrm{L}$ of $5 \% \mathrm{ACN} / 0.1 \%$ FA and 5 microliters of each sample were analyzed by LC-MS/MS on a 6520 Q-TOF mass spectrometer (Agilent Technologies, Santa Clara, CA, 
USA) coupled to a chip-based chromatographic interface. A Large Capacity Chip was used and peptides were separated in the $\mathrm{C} 18$ nano-column $(150 \mathrm{~mm} \times 75 \mu \mathrm{m} \mathrm{ID)}$ at a flow rate of $0.3 \mu \mathrm{L} / \mathrm{min}$. $\mathrm{H}_{2} \mathrm{O} /$ FA $0.1 \%$ and ACN/FA $0.1 \%$ were used as eluents $\mathrm{A}$ and $\mathrm{B}$, respectively. Peptides were separated with a linear gradient of eluent $B$ from $5 \%$ to $50 \%$ in 15 min and analyzed with a data dependent mode acquisition: for each MS scan, $6 \mathrm{MS} / \mathrm{MS}$ spectra were acquired for the most intense ions. Scan speeds were 3 MS spectra/sec and 3 MS/MS spectra/sec.

Raw data files were converted into Mascot Generic Format (MGF) files with MassHunter Qualitative Analysis Software version B.03.01 (Agilent Technologies, Santa Clara, CA, USA) and searched with Mascot Search Engine (version 2.2.4, Matrix Science, London, UK) through the Proteome Discoverer Software interface (version 1.4, Thermo Fisher Scientific, Waltham, MA, USA). Spectra were searched against the human section of the Uniprot database (version July 2018, 95,057 sequences) using the following parameters: enzyme specificity was set to trypsin with 1 missed cleavage allowed, precursor and fragment ions tolerance were $20 \mathrm{ppm}$ and $0.05 \mathrm{Da}$, respectively. Carbamidomethylcysteine and oxidation of methionine were set as fixed modification and variable modification, respectively. MS/MS spectra containing less than 5 peaks or with a total ion count lower than 50 were discarded. The algorithm Percolator was used to assess the False Discovery Rate (FDR) thanks to a concomitant search against the corresponding randomized database. Proteins were considered as positive hits if for each protein at least 2 unique peptides were identified with high confidence (FDR $<0.01 \%$ ). For some protein spots that did not return any significant hit, a Peptide Mass Fingerprint (PMF) was also performed with Mascot. All identified proteins were verified to have phosphorylated residues in PhosphoSitePlus database (www.phosphosite.org).

\subsection{Western Blotting}

Phosphoprotein extracts $(20 \mu \mathrm{g})$ from IMAC columns used for 2-DE were separated by $12 \%$ and then transferred to a nitrocellulose membrane. The Western blotting procedure for phosphoproteins was conducted as previously described [21]. The membrane was blocked by treatment with $5 \%$ BSA in TBS-tween 20. After BSA saturation the membrane was incubated overnight at $4{ }^{\circ} \mathrm{C}$ with 1:200 diluted primary rabbit polyclonal antibody against Endoplasmic reticulum chaperone BiP (HSPA5), with 1:300 diluted primary rabbit polyclonal antibody against heat shock protein beta-1 (HSPB1), and 1:800 diluted primary rabbit polyclonal antibody against Vinculin (VINC). The membrane was washed three times in TBST for $10 \mathrm{~min}$, and then incubated for $90 \mathrm{~min}$ at $4{ }^{\circ} \mathrm{C}$ with a horseradish peroxidase-conjugated anti-rabbit immunoglobulin G antibody (Sigma-Aldrich, St. Louis, MO, USA; Merck KGaA, Burlington, VT, USA) at 1:3.000 dilution. Protein expression was visualized by chemiluminescence (SuperSignal West Pico Chemiluminescent Substrate; Thermo Fisher Scientific, Inc., Waltham, MA, USA), and the intensity of the signals was quantified by VersaDoc Imaging System (Bio-Rad Laboratories, Inc.). The intensities of the immunostained bands were normalized with the protein intensities measured by Red Ponceau (Sigma-Aldrich, St. Louis, MO, USA; Merck KGaA, Burlington, VT, USA) from the same blot.

\subsection{Ingenuity Pathway (IPA) and PANTHER Analysis}

Differentially enriched proteins identified by MS in the leiomyoma were analyzed by IPA (Qiagen $\mathrm{GmbH}$, Hilden, Germany). In IPA, we considered $P<0.05$ as a statistically significant value. Selected genes were used to generate bio-functions. For the filter summary, only associations where confidence was high (predicted) or that had been experimentally observed were considered. These proteins were analyzed by PANTHER 11.0 (Protein Analysis Through Evolutionary Relationships; http://www.pantherdb.org) and Gene Ontology (http://amigo.geneontology.org/rte). Proteins were then classified according to their involvement in biological processes, molecular function, protein class, and pathways. Since the majority of the proteins identified participated in multiple processes, only the most relevant ones were reported. 


\subsection{Statistical Analysis}

Statistical analyses were carried out with the non-parametric Wilcoxon signed-rank test for matched samples for both 2-DE and Western blot data. $P<0.05$ was considered to indicate a statistically significant difference. All analyses were conducted with Stata/IC 14.1 for Windows (StataCorp LP, College Station, TX, USA).

\section{Results}

\subsection{Identification of Differentially Phosphorylated Proteins with Pro-Q Diamond Gel Stain}

After electrophoresis, gels were stained with Pro-Q Diamond for phosphoproteins (P) and with SYPRO Ruby for total proteins (T). Correlation analysis of gel-pairs performed well, with an average matching efficiency of approximately $80 \%$. As shown in Figure 1, ten protein spots belonging to seven different putative phosphoproteins were found to be with a significant different abundance in leiomyoma samples if compared to the myometrium. The spot volume of two of these proteins [corresponding to Apolipoprotein E (APOE) (spot6) and 60S acidic ribosomal protein P2 (RPLP2) (spot7)] was significantly higher (>1.5-fold) (Table 1) in the leiomyoma, while for five proteins (Caveolae-associated protein 1 (CAVN1) (spot1,2,3,4), Heterogeneous nuclear ribonucleoproteins C1/C2 (HNRNPC) (spot5), Caveolae-associated protein 1 (PTRF) (spot8), Apolipoprotein D (APOD) (spot9) and Myosin light chain kinase, smooth muscle (MYLK) (spot10)) the relative spot volumes were significantly lower (<0.6-fold, Figure 1$)$.

Table 1. List of putative phosphoproteins with a significant different abundance in the leiomyoma compared to myometrium, as identified by mass spectrometry.

\begin{tabular}{|c|c|c|c|c|c|c|}
\hline $\begin{array}{c}\text { Accession } \\
\text { No }\end{array}$ & Spot No & Protein Description & $\begin{array}{c}\text { Gene } \\
\text { Symbol }\end{array}$ & $\begin{array}{l}\text { Protein } \\
\text { Score }\end{array}$ & $\begin{array}{c}\text { Fold } \\
\text { Change * }\end{array}$ & $P$-Value \\
\hline P30101 & 22 & $\begin{array}{c}\text { Protein } \\
\text { disulfide-isomerase A3 }\end{array}$ & PDIA3 & 295 & 5.2 & 0.0277 \\
\hline H9KV75 & 25 & Alpha-actinin-1 & ACTN1 & 93 & 4.9 & 0.0431 \\
\hline P11021 & 29 & $\begin{array}{c}78 \mathrm{kDa} \\
\text { glucose-regulated } \\
\text { protein }\end{array}$ & HSPA5 & 675 & 4.6 & 0.045 \\
\hline P05387 & 7 & $\begin{array}{c}\text { 60S acidic ribosomal } \\
\text { protein P2 }\end{array}$ & RPLP2 & 121 & 4.5 & 0.0422 \\
\hline H0YJW3 & 32 & $\begin{array}{l}\text { Alpha-actinin-1 } \\
\text { (Fragment) }\end{array}$ & ACTN1 & 141 & 3.8 & 0.0273 \\
\hline Q5JRR6 & 34 & $\begin{array}{c}\text { Ubiquitin-like } \\
\text { modifier-activating } \\
\text { enzyme } 1\end{array}$ & UBA1 & 64 & 3.8 & 0.0277 \\
\hline A0A087WU08 & 18 & Haptoglobin & $\mathrm{HP}$ & 159 & 3.4 & 0.0180 \\
\hline A0A087WU08 & 19 & Haptoglobin & $\mathrm{HP}$ & 50.8 & 3.3 & 0.0180 \\
\hline E9PFZ2 & 30 & Ceruloplasmin & $\mathrm{CP}$ & 154 & 3.2 & 0.0431 \\
\hline H7BZ94 & 41 & $\begin{array}{c}\text { Protein } \\
\text { disulfide-isomerase }\end{array}$ & $\mathrm{P} 4 \mathrm{HB}$ & 272 & 3.2 & 0.0431 \\
\hline A0A0C4DGB6 & 26 & Serum albumin & ALB & 43 & 3 & 0.0220 \\
\hline H7C3T4 & 15 & Peroxiredoxin-4 & PRDX4 & 159 & 2.85 & 0.0273 \\
\hline
\end{tabular}


Table 1. Cont.

\begin{tabular}{|c|c|c|c|c|c|c|}
\hline $\begin{array}{l}\text { Accession } \\
\text { No }\end{array}$ & Spot No & Protein Description & $\begin{array}{l}\text { Gene } \\
\text { Symbol }\end{array}$ & $\begin{array}{l}\text { Protein } \\
\text { Score }\end{array}$ & $\begin{array}{c}\text { Fold } \\
\text { Change * }\end{array}$ & $P$-Value \\
\hline Q5JRR6 & 33 & $\begin{array}{c}\text { Ubiquitin-like } \\
\text { modifier-activating enzyme } 1\end{array}$ & UBA1 & 128 & 2.7 & 0.0273 \\
\hline P02790 & 27 & Hemopexin & HPX & 69 & 2.56 & 0.0431 \\
\hline Q3BDU5 & 20 & Prelamin-A/C & LMNA & 395 & 2.5 & 0.0277 \\
\hline H7BZ94 & 40 & Protein disulfide-isomerase & P4HB & 72 & 2.3 & 0.0277 \\
\hline P18206-2 & 38 & Isoform 1 of Vinculin & VINC & 198 & 2.25 & 0.0277 \\
\hline E9PFZ2 & 31 & Ceruloplasmin & $\mathrm{CP}$ & 237 & 2.25 & 0.0431 \\
\hline P30101 & 25 & Protein disulfide-isomerase A3 & PDIA3 & 808 & 2.23 & 0.0220 \\
\hline P10809 & 39 & $60 \mathrm{kDa}$ heat shock protein & HSPD1 & 234 & 2.2 & 0.0431 \\
\hline P02649 & 6 & Apolipoprotein E & APOE & 230 & 2.15 & 0.0431 \\
\hline P01023 & 37 & Alpha-2-macroglobulin & A2M & 52 & 2.14 & 0.0431 \\
\hline P01023 & 12 & Peroxiredoxin-2 & PRDX2 & 64 & 2.1 & 0.0180 \\
\hline P04792 & 14 & Heat shock protein beta- 1 & HSPB1 & 151 & 2 & 0.0277 \\
\hline P01024 & 17 & Complement C3 & $\mathrm{CO} 3$ & 171 & 2 & 0.0431 \\
\hline E9PN50 & 21 & $\begin{array}{l}\text { 26S protease regulatory subunit } \\
6 \mathrm{~A} \text { (Fragment) }\end{array}$ & PSMC3 & 191 & 2 & 0.0425 \\
\hline P30101 & 23 & Protein disulfide-isomerase A3 & PDIA3 & 79 & 2 & 0.0220 \\
\hline B7ZAR1 & 24 & $\begin{array}{l}\text { T-complex protein } 1 \text { subunit } \\
\text { epsilon }\end{array}$ & CCT5 & 150 & 2 & 0.0277 \\
\hline P28070 & 13 & Proteasome subunit beta type- 4 & PSMB4 & 168 & 1.75 & 0.0431 \\
\hline J3KRH2 & 11 & Haptoglobin (Fragment) & $\mathrm{HP}$ & 342 & 1.7 & 0.0178 \\
\hline P08603 & 36 & Complement factor $\mathrm{H}$ & $\mathrm{CFH}$ & 69 & 1.7 & 0.0273 \\
\hline Q13409-2 & 28 & $\begin{array}{c}\text { Isoform 2B of Cytoplasmic } \\
\text { dynein } 1 \text { intermediate chain } 2\end{array}$ & DYNC1/2 & 85 & 1.51 & 0.0180 \\
\hline Q6NZI2 & 4 & Caveolae-associated protein 1 & CAV1 & 75 & 0.65 & 0.0277 \\
\hline Q6NZI2 & 2 & Caveolae-associated protein 1 & CAV1 & 161 & 0.43 & 0.03 \\
\hline Q6NZI2 & 3 & Caveolae-associated protein 1 & CAV1 & 127 & 0.37 & 0.0180 \\
\hline G3V5V7 & 5 & $\begin{array}{l}\text { Heterogeneous nuclear } \\
\text { ribonucleoproteins C1/C2 } \\
\text { (Fragment) }\end{array}$ & HNRNPC & 69 & 0.29 & 0.0180 \\
\hline Q6NZI2-3 & 8 & $\begin{array}{l}\text { Isoform } 3 \text { of Polymerase I and } \\
\text { transcript release factor }\end{array}$ & PTRF & 238 & 0.11 & 0.0422 \\
\hline C9JF17 & 9 & Apolipoprotein D & APOD & 103 & 0.1 & 0.0422 \\
\hline Q15746-10 & 10 & $\begin{array}{l}\text { Isoform } 8 \text { of Myosin light chain } \\
\text { kinase, smooth muscle }\end{array}$ & MYLK & 51 & 0.08 & 0.03 \\
\hline P17661 & 16 & Desmin & DES & 787 & 0.06 & 0.0180 \\
\hline Q6NZI2 & 1 & Caveolae-associated protein 1 & CAV1 & 63 & 0.03 & 0.0178 \\
\hline
\end{tabular}

* Fold change was defined as the ratio of the mean $\% \mathrm{~V}$ according to the formula $\% \mathrm{~V}=\mathrm{Vsingle} \mathrm{spot} / \mathrm{Vtotal}$ spot of cases vs. controls. 
A

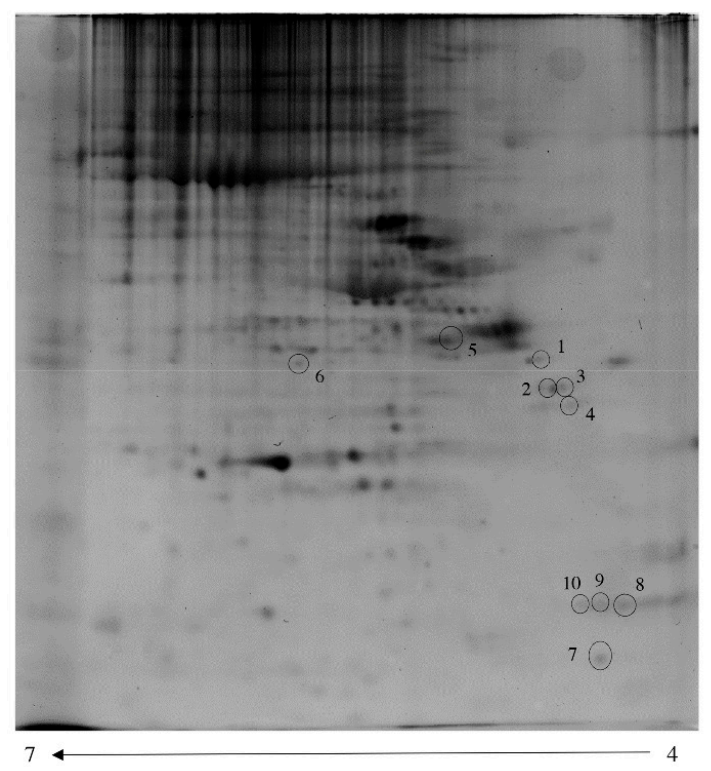

Myometrium

B.

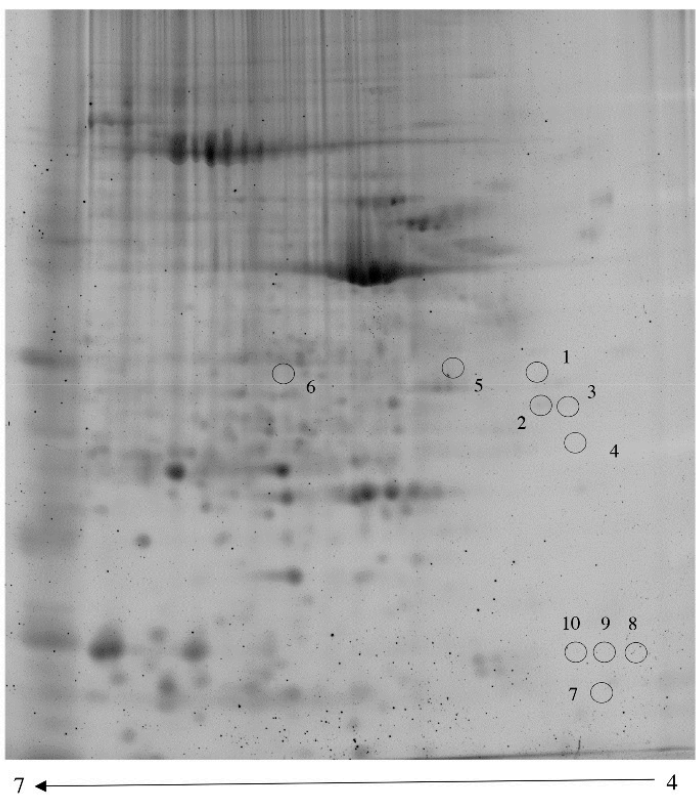

Myometrium

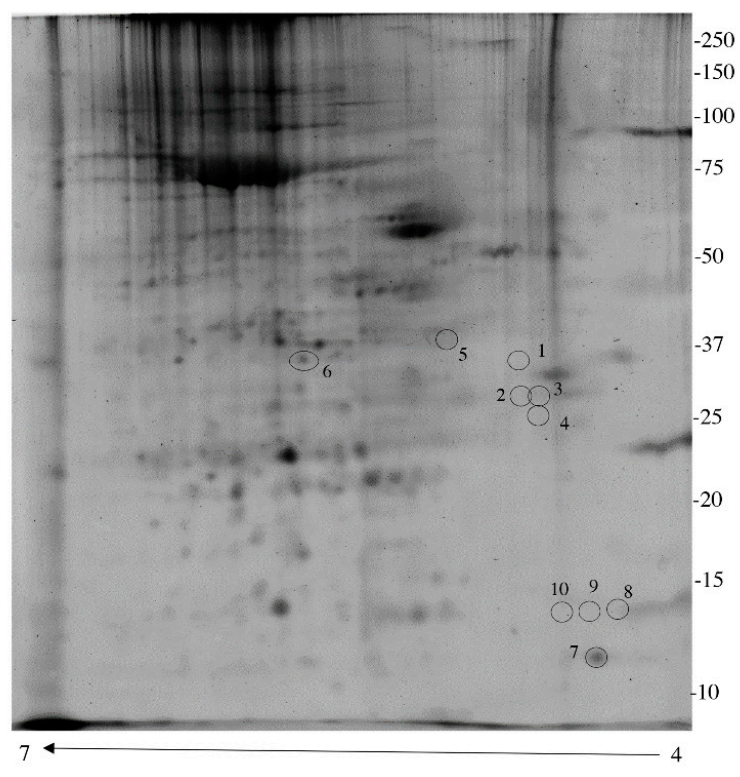

Leiomyoma

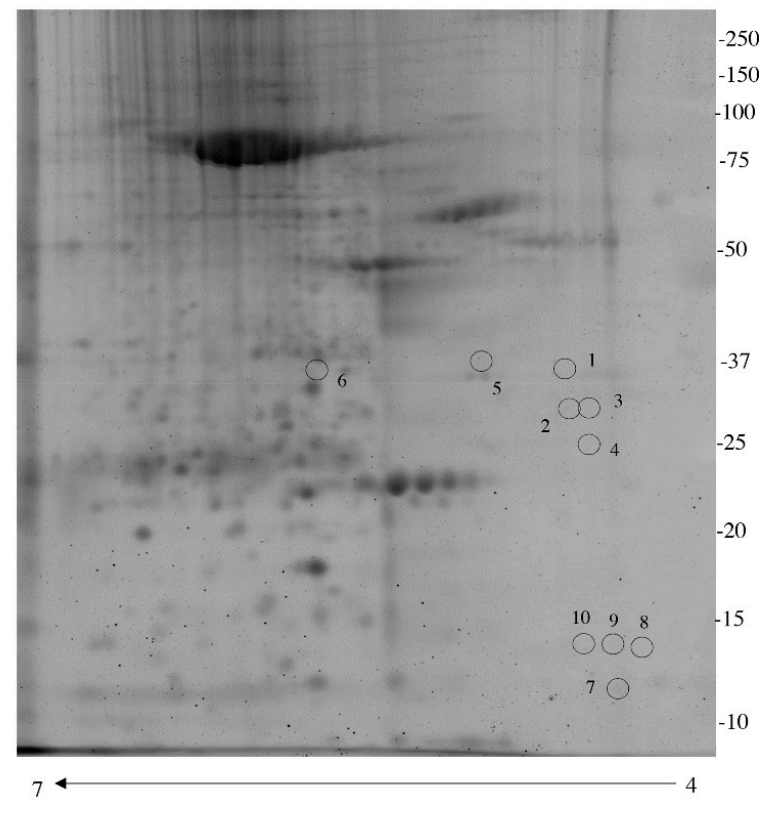

Leiomyoma

Figure 1. (A) Images of gels stained with Pro-Q Diamond to detect phosphoproteins. (B.) Images of gels stained with SYPRO Ruby for total proteins.

\subsection{Enrichment of Immobilized Metal Affinity Chromatography (IMAC)}

The next step for the identification of differentially phosphorylated proteins in the leiomyoma was the using of IMAC. This method, although not completely specific, allows for an efficient enrichment of phosphoproteins. By using 2-DE fluorescence, we compared the enriched phosphoproteome of the myometrial and leiomyoma tissues. An average of 1800 spots was detected on gels for both types of enriched phosphoproteomes. Correlation of gel-pairs performed with an average matching efficiency of $\sim 80 \%$. The analysis revealed 35 protein spots with a significant different abundance (Figure 2 ) in the leiomyoma compared to myometrium. We considered only spots supposedly corresponding to 
phosphoproteins, with fold change in $\% \mathrm{~V} \geq 1.5$ or $\leq 0.6$ in intensity and that were statistically significant $(P<0.05)$. Of these spots, 34 were upregulated $(>1.5$-fold $)$ while one was significantly downregulated (<0.6-fold) (Table 1). The 33 putative phosphoproteins were identified using a nano-LC-ESI-Q-TOF system and Mascot search engine, as described above.
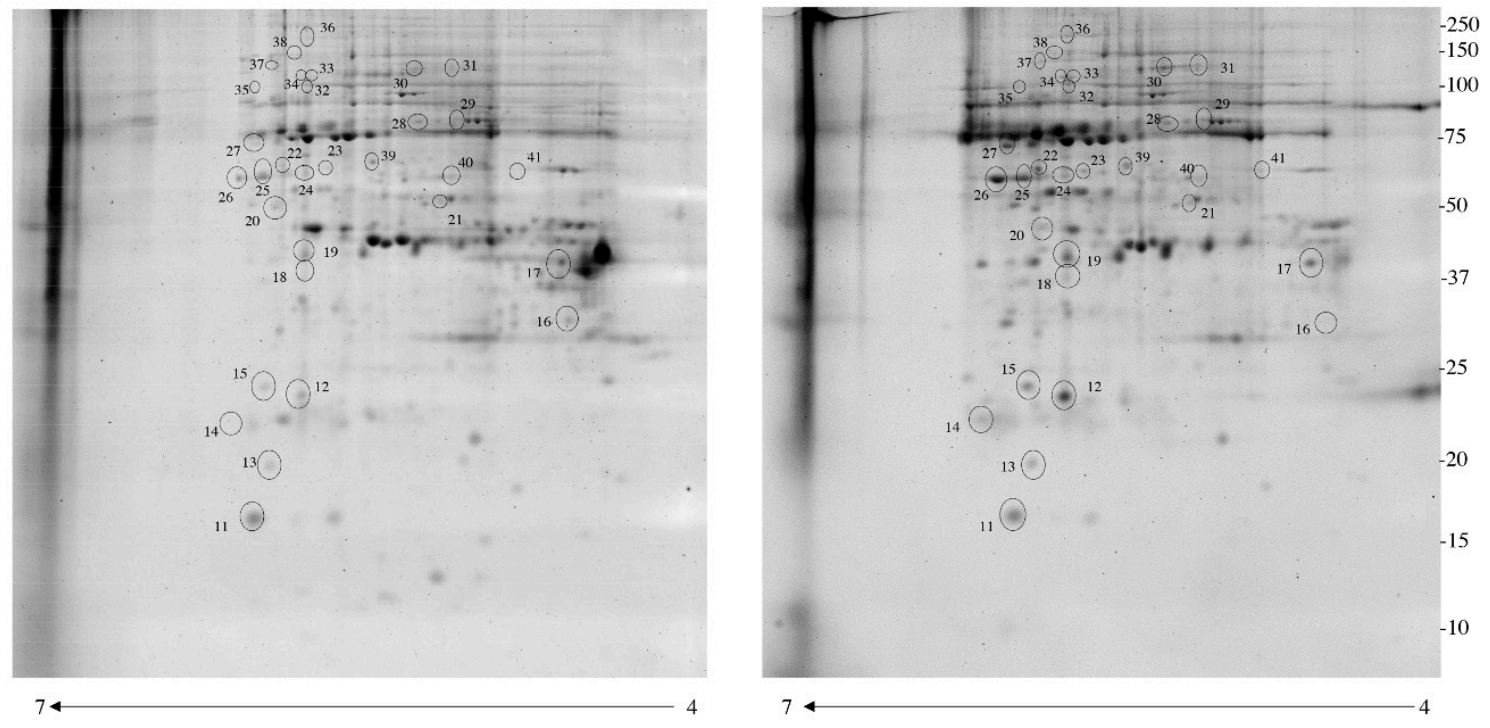

Figure 2. Two-dimensional electrophoresis map of normal myometrium and leiomyoma phosphoproteome enriched by IMAC columns. Immobilized $\mathrm{pH}$ gradient 4-7 strips were used for the first dimension and $12 \%$ polyacrylamide gel was used for the second dimension. The numbered circles indicate the differentially phosphorylated spots.

\subsection{Functional Analysis of the Leiomyoma Phosphoproteome}

The identified proteins were divided into groups, based on the PANTHER classification system according to their biological processes, molecular function, protein class. In terms of biological processes (Figure S1), the proteins were grouped into four main categories: response to stimulus, cellular process, metabolic process, biological regulation. For molecular function (Figure S2), proteins were grouped into: catalytic activity, binding, molecular function regulator, and transporter activity. For protein class (Figure S3), proteins were grouped in five main categories: hydrolase, signaling molecule, oxidoreductase, enzyme modulator, and defense/immunity protein. For cellular component (Figure S4), proteins were grouped in four main categories: cell parts, organelle, protein-containing complex, extracellular region. For pathway analysis (Figure S5), proteins were grouped in 15 pathways. Ten of these (FAS signaling pathway, p38 MAPK pathway, VEGF signaling pathway, Cytoskeletal regulation by Rho GTPase, Integrin signaling pathway, Apoptosis signaling pathway, Angiogenesis, Gonadotropin-releasing hormone receptor pathway, Ubiquitin-proteasome pathway, Inflammation mediated by chemokine and cytokine signaling pathway) are tumorigenic signaling pathways.

Proteins differentially enriched by IMAC in the leiomyoma compared to the myometrium were used in the core analysis with IPA software. The top networks in which these proteins are involved correspond to 1) Apoptosis (Figure S6A.) and 2) Cell survival (Figure S6B.). In the apoptosis network, 18 putative phosphoproteins are involved. Of these, CFH (spot36), DYNC (spot28), HSPA5 (spot29), HSPB1 (spot14), HSPD1 (spot39), PDRX2 (spot12), UBA1 (spot33,34), A2M (spot37) are involved in apoptosis inhibition, while HSPA5, HSPB1, HSPD1, LMNA (spot20), P4HB (spot41,42), PRDX2, PSMB4 (spot13) are involved in cell survival. HSPA5, HSPB1, HSPD1 and PDRX2 are involved in both inhibition of apoptosis and cell survival. 


\subsection{Immunohistochemical Study of Altered Proteins}

In this study, we proceeded to verify by immunoblot the alteration of three putative phosphorylated proteins: HSPA5, HSPB1, and VINC. After IMAC enrichment, the abundance of these proteins in five leiomyomas was compared to the matched normal myometrial tissue samples (previously used in 2-DE analysis) by Western blot analysis (Figure 3). The five patients shown in the figure are representative of the total seven patients included in the study, based on both 2-DE and Western blotting phosphorylation trend of HSPB1, HSPA5, and VINC (higher in leiomyoma compared to myometrium). We selected HSPB1 and HSP5A because, based on our bioinformatic analysis, these two proteins are associate to the inhibition of apoptosis and cell proliferation. We selected VINC because the antibody is commercially available.

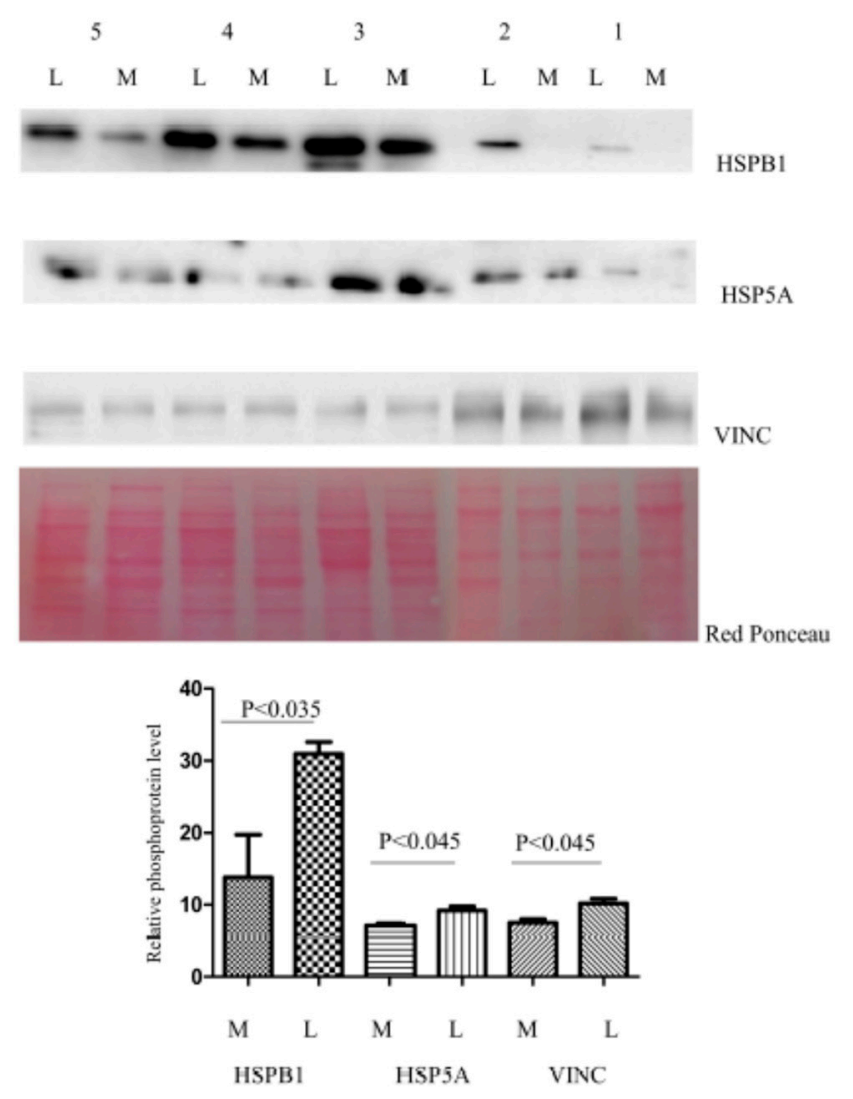

Figure 3. Western blot analysis was utilized to confirm the alteration of phosphorylation of proteins HSPB1, VINC and HSPA5 in paired myometrium (M) and leiomyoma (L). The intensity of immunostained bands was normalized against the total protein intensities measured from the same blot stained with Red Ponceau. Number 1-5 indicate the patients. The bar graph shows the relative expression (band density) of HSPB1, VINC and HSPA5 in the myometrium and the leiomyoma. Results are shown as a histogram $(P<0.05)$ and each bar represents mean \pm standard deviation.

\section{Discussion}

Several studies have shown that the phosphorylation of certain proteins like ER, AKT, RTK, MAPK, MEK, and GSK3 lead to increased leiomyoma cell proliferation $[8,9,22]$. For the first time, we conducted a proteomic study on leiomyoma and normal myometrium to identify putative phosphoproteins and the pathways in which these proteins are involved and that are altered in the tumor as compared to the normal tissue. By using a combination of IMAC enrichment, 2-DE, Diamond Pro-Q staining, and mass spectrometry, we identified 32 putative phosphoproteins differentially phosphorylated/expressed in the leiomyoma as compared to the myometrium (Table 1). We identified several tumor-related 
pathways in which these proteins are involved and that could be implicated in the modulation of leiomyoma growth. According to the data reported in the PhosphoSitePlus database, all identified proteins were already reported to be phosphorylated in vivo, suggesting that the enrichment procedure was effective in isolating mainly phosphorylated proteins. The altered abundance or phosphorylation level of some of these proteins was confirmed by an independent method (IMAC enrichment, 2-DE, and Western blotting). However, we did not try to identify the phosphorylation site(s) that could be altered in these proteins and therefore our validation could not be performed using antibodies against specific phosphorylated sites. Nonetheless, we could confirm a significant difference of these proteins in tumor vs. normal tissue, either due to an overall altered abundance of the proteins or to an altered phosphorylation level.

Jamaluddin MFB et al. [14] conducted a proteomic study for the characterization of fibroid ECM proteins. They identified several proteins up regulated in the leiomyoma: POSTN, TNC, COL3A1, COL24A1, and ASPN. Another proteomic study conducted by Liu Y et al. [23] identified TRADD as a potential biomarker in human uterine leiomyoma.

The Fas receptor (CD95) mediates apoptotic signaling initiated by interaction with surface expressed FasL on other cells [24]. Mutations in the Fas signaling pathway can result in cell hyperproliferation [25]. Once the complex Fas-FasL has been created, the apoptotic program should be activated via recruitment of signaling adaptor molecules to the Fas receptor [26].

Lamins constitute a class of intermediate filaments, which, during mitosis, are dissociated by phosphorylation-dependent mechanisms [27]. To date, no data regarding the activity of the phosphorylated form of Lamin A have been reported. According to Foster CR and colleagues, increased mobility of phosphorylated Lamin A could be one way to promote nuclear deformability and cell migration [28].

The p38 MAPK pathway is regulated by stress, cytokines and mediates a wide variety of cellular behaviors, such as cell differentiation, proliferation, migration, invasion, and cell death [29].

The VEGF pathway represents the signal transduction cascade, initiated after this protein binds to its receptor VEGFR-2, leading to survival, increased proliferation, and migration of blood endothelial cells required for angiogenesis [30]. In the leiomyoma, VEGF is overexpressed and leads to tumor growth in xenografts mice [31]. In this study, we identified four putative phosphoproteins involved in anti-apoptotic and cell survival processes, events that promote cell growth.

HSPB1 plays a role in stress resistance and actin organization. In response to environmental stress, the encoded protein translocates from the cytoplasm to the nucleus and functions as a molecular chaperone that promotes the correct folding of other proteins and plays an essential role in the differentiation of a wide variety of cell types [32]. This protein is correlated with poor clinical outcomes in several human cancers, promoting cancer cell proliferation and metastases, while protecting cancer cells from apoptosis [33]. In our previous study [34]. We predicted the phosphorylation of HSPB1 in the leiomyoma. In this study, we identified this protein as supposedly differentially phosphorylated in the leiomyoma, suggesting a possible role of phosphorylated HSPB1 in promoting cell survival in cancer [35].

HSPA5 is another putative phosphoprotein identified in this study, involved in cell survival and anti-apoptotic events. This protein plays a central role in regulating the unfolded protein response (UPR), is an obligatory component of autophagy in mammalian cells, and plays an important role in cellular adaptation and oncogenic survival [36,37]. This protein undergoes phosphorylation at specific serine and tyrosine residues, which influences their oligomerization into larger, multimeric aggregates [38]. Lim et al. suggest the possibility of a direct role of the phosphorylation of HSP5A in human breast cancer tissue [39].

HSPD1 is implicated in mitochondrial protein import and macromolecular assembly [40]. This chaperone promotes the refolding and proper assembly of unfolded polypeptides generated under stress conditions in the mitochondrial matrix [41]. The tyrosine phosphorylation of HSPD1 is essential for the maturation of ULBP2 (cell surface proteins that are present in transformed and stressed cells and 
ligands for NK cells) [42]. In cancer, the loss of ULBP2 leads to reduced NK cell-mediated cytotoxicity and cytokine production [43].

PRDX2 is the last of the identified putative phosphoproteins involved in anti-apoptotic and cell survival processes. PRDX2 is a member of the peroxiredoxin family of antioxidant enzymes, involved in redox regulation of the cell [44]. This enzyme influences several cellular processes involving proliferation, survival, and apoptosis, which suggests a possible role for Prdx2 in the maintenance of cancer cell [45]. Qu D et al. suggest that the Cdk5 phosphorylate PRDX2 [46]. This phosphorylation reduces PRDX2 activity thus increasing oxidative stress and cell proliferation [46]. We think that a similar mechanism may be present in the leiomyoma. Panther analysis revealed a significant enrichment of GO terms for several important processes, like metabolic processes and cellular biogenesis. Some of these metabolic processes have been previously described by our group [25]. pointing to a particular importance of metabolism in leiomyoma growth. In addition, our Panther analysis reveals that many proteins identified in our study are enzymes, are related to oxidative stress, and reside mostly inside the cell.

A scrutiny of the literature reveals that three kinases are known to be responsible for the phosphorylation of several proteins that we have identified in this study. In particular, MAPK, PKC, and Cdk5 were reported to phosphorylate HSPB1 [47], HSPA5 [48], HSPD1 [49], and PRDX2 [47]. Interestingly, both MAPK and PKC are known to be involved in leiomyoma development [9] and in general all three kinase are related with cancer cell progression and proliferation [47].

Several studies have been conducted to highlight the effects of various kinase inhibitors in the leiomyoma. Shushan A et al. [50] used the AG1478 an EGFR kinase blocker in leiomyoma cells. Leiomyoma cell growth is inhibited by AG1478, and is unaffected by the presence of physiological concentrations of estradiol and progesterone. In another paper, Shushan A et al. [51] evaluate the efficiency of genistein (a plant flavonoid) and the new protein tyrosine kinase inhibitor TKS050 in the inhibition of autophosphorylation of EGFR and downstream signal transduction events, including cell proliferation and cell cycle progression.

The ubiquitination is a poorly studied process in leiomyoma, even though it is known that the blocking of this process is related to tumor growth. An example is the switching of the ubiquitin/proteasome-dependent degradation of $R X R \alpha$ by phosphorylation in leiomyomas. These events may be responsible for the accumulation of $R X R \alpha$ and the consequent dysregulation of retinoic acid target genes [52].

UBA1 catalyzes the first step in ubiquitin conjugation to mark cellular proteins for degradation through the ubiquitin-proteasome system [53]. The role of this enzyme has been linked to DNA repair, for response to replication stress, cell cycle regulation, apoptosis, and cancer [54]. UBA1 inhibitors lead to an unfolded protein response and induces cell death in malignant cells over normal cells [55].

\section{Conclusions}

In conclusion, our study highlights the involvement of the phosphoproteome in leiomyoma growth. We identified several pathways associated with tumor development and phosphoproteins involved in the inhibition of apoptosis and cell proliferation. All these data show the existence of a relation between phosphorylation and leiomyoma development. Further studies are needed to understand the role of phosphorylation in leiomyoma growth. In our opinion, our data represent a step forward in the difficult understanding of the molecular mechanisms that lead to the formation and development of the leiomyoma.

Supplementary Materials: The following are available online at http://www.mdpi.com/2077-0383/8/5/691/s1, Figure S1: PANTHER classification of identified proteins in the leiomyoma according to their biological process, Figure S2: PANTHER classification of identified proteins in the leiomyoma according to their molecular function, Figure S3: PANTHER classification of identified proteins in the leiomyoma according to their protein class, Figure S4: PANTHER classification of identified proteins in the leiomyoma according to their cellular component, Figure S5: PANTHER classification of identified proteins in signaling pathways, Figure S6: Network build up from one of the most significant bio-functions: 1. Apoptosis, 2. Cell survivor. 
Author Contributions: Conceived of and designed the experiments: G.R., F.S.; Performed the experiments: B.U., G.A., I.B., D.L., M.A. Analyzed the data: L.M., B.U., G.A. Wrote the paper: G.D.L., F.R., I.P., G.S., B.U., L.M. and G.A.

Conflicts of Interest: The authors declare no conflict of interest.

\section{References}

1. Kim, J.J.; Sefton, E.C. The role of progesterone signaling in the pathogenesis of uterine leiomyoma. Mol. Cell. Endocrinol. 2012, 358, 223-231. [CrossRef] [PubMed]

2. Lv, J.; Zhu, X.; Dong, K.; Lin, Y.; Hu, Y.; Zhu, C. Reduced expression of 14-3-3 $\gamma$ in uterine leiomyoma as identified by proteomics. Fertil. Steril. 2008, 90, 1892-1898. [CrossRef] [PubMed]

3. Moravek, M.B.; Yin, P.; Ono, M.; Coon, J.S.; Dyson, M.T.; Navarro, A.; Marsh, E.E.; Chakravarti, D.; Kim, J.J.; Wei, J.J.; et al. Ovarian steroids, stem cells and uterine leiomyoma: Therapeutic implications. Hum. Reprod. Update 2015, 21, 1-12. [CrossRef]

4. Ura, B.; Di Lorenzo, G.; Romano, F.; Monasta, L.; Mirenda, G.; Scrimin, F.; Ricci, G. Interstitial Fluid in Gynecologic Tumors and Its Possible Application in the Clinical Practice. Int. J. Mol. Sci. 2018, $19,4018$. [CrossRef]

5. Chen, I.H.; Xue, L.; Hsu, C.C.; Paez, J.S.; Pan, L.; Andaluz, H.; Wendt, M.K.; Iliuk, A.B.; Zhu, J.K.; Tao, W.A. Phosphoproteins in extracellular vesicles as candidate markers for breast cancer. Proc. Natl. Acad. Sci. USA 2017, 114, 3175-3180. [CrossRef] [PubMed]

6. Fuhs, S.R.; Meisenhelder, J.; Aslanian, A.; Ma, L.; Zagorska, A.; Stankova, M.; Binnie, A.; Al-Obeidi, F.; Mauger, J.; Lemke, G.; et al. Monoclonal 1- and 3-Phosphohistidine Antibodies: New Tools to Study Histidine Phosphorylation. Cell 2015, 162, 198-210. [CrossRef] [PubMed]

7. Iliuk, A.B.; Arrington, J.V.; Tao, W.A. Analytical challenges translating mass spectrometry-based phosphoproteomics from discovery to clinical applications. Electrophoresis 2014, 35, 3430-3440. [CrossRef]

8. Hermon, T.L.; Moore, A.B.; Yu, L.; Kissling, G.E.; Castora, F.J.; Dixon, D. Estrogen receptor alpha (ERalpha) phospho-serine-118 is highly expressed in human uterine leiomyomas compared to matched myometrium. Virchows Arch. 2008, 453, 557-569. [CrossRef]

9. Borahay, M.A.; Al-Hendy, A.; Kilic, G.S.; Boehning, D. Signaling Pathways in Leiomyoma: Understanding Pathobiology and Implications for Therapy. Mol. Med. 2015, 21, 242-256. [CrossRef]

10. Yu, L.; Moore, A.B.; Dixon, D. Receptor tyrosine kinases and their hormonal regulation in uterine leiomyoma. Semin. Reprod. Med. 2010, 28, 250-259. [CrossRef]

11. Derynck, R.; Zhang, Y.E. Smad-dependent and Smad-independent pathways in TGF-beta family signalling. Nature 2003, 425, 577-584. [CrossRef]

12. Chegini, N.; Luo, X.; Ding, L.; Ripley, D. The expression of Smads and transforming growth factor beta receptors in leiomyoma and myometrium and the effect of gonadotropin releasing hormone analogue therapy. Mol. Cell. Endocrinol. 2003, 209, 9-16. [CrossRef] [PubMed]

13. Karra, L.; Shushan, A.; Ben-Meir, A.; Rojansky, N.; Klein, B.Y.; Shveiky, D.; Levitzki, R.; Ben-Bassat, H. Changes related to phosphatidylinositol 3-kinase/Akt signaling in leiomyomas: Possible involvement of glycogen synthase kinase 3alpha and cyclin D2 in the pathophysiology. Fertil. Steril. 2010, 93, 2646-2651. [CrossRef]

14. Nierth-Simpson, E.N.; Martin, M.M.; Chiang, T.C.; Melnik, L.I.; Rhodes, L.V.; Muir, S.E.; Burow, M.E.; McLachlan, J.A. Human uterine smooth muscle and leiomyoma cells differ in their rapid 17beta-estradiol signaling: Implications for proliferation. Endocrinology 2009, 150, 2436-2445. [CrossRef]

15. Yu, L.; Saile, K.; Swartz, C.D.; He, H.; Zheng, X.; Kissling, G.E.; Di, X.; Lucas, S.; Robboy, S.J.; Dixon, D. Differential expression of receptor tyrosine kinases (RTKs) and IGF-I pathway activation in human uterine leiomyomas. Mol. Med. 2008, 14, 264-275. [CrossRef]

16. Ura, B.; Scrimin, F.; Arrigoni, G.; Franchin, C.; Monasta, L.; Ricci, G. A Proteomic Approach for the Identification of Up-Regulated Proteins Involved in the Metabolic Process of the Leiomyoma. Int. J. Mol. Sci. 2016, 17, 540. [CrossRef] [PubMed]

17. Jamaluddin, M.F.B.; Nahar, P.; Tanwar, P.S. Proteomic Characterization of the Extracellular Matrix of Human Uterine Fibroids. Endocrinology 2018, 159, 2656-2669. [CrossRef] 
18. Ura, B.; Scrimin, F.; Arrigoni, G.; Athanasakis, E.; Aloisio, M.; Monasta, L.; Ricci, G. Abnormal expression of leiomyoma cytoskeletal proteins involved in cell migration. Oncol. Rep. 2016, 35, 3094-3100. [CrossRef]

19. Wang, Z.; Zhang, C.; Li, Z.; Shen, Q.; Zhang, D. Comparative analysis of muscle phosphoproteome induced by salt curing. Meat. Sci. 2017, 133, 19-25. [CrossRef]

20. Ura, B.; Monasta, L.; Arrigoni, G.; Franchin, C.; Radillo, O.; Peterlunger, I.; Ricci, G.; Scrimin, F. A proteomic approach for the identification of biomarkers in endometrial cancer uterine aspirate. Oncotarget 2017, 8 , 109536-109545. [CrossRef]

21. Khang, R.; Park, C.; Shin, J.H. The biguanide metformin alters phosphoproteomic profiling in mouse brain. Neurosci. Lett. 2014, 579, 145-150. [CrossRef] [PubMed]

22. Barbarisi, A.; Petillo, O.; Di Lieto, A.; Melone, M.A.; Margarucci, S.; Cannas, M.; Peluso, G. 17-beta estradiol elicits an autocrine leiomyoma cell proliferation: Evidence for a stimulation of protein kinase-dependent pathway. J. Cell Physiol. 2001, 186, 414-424. [CrossRef]

23. Liu, Y.; Lu, D.; Sheng, J.; Luo, L.; Zhang, W. Identification of TRADD as a potential biomarker in human uterine leiomyoma through iTRAQ based proteomic profiling. Mol. Cell. Probes 2017, 36, 15-20. [CrossRef]

24. Krammer, P.H. CD95's deadly mission in the immune system. Nature 2000, 407, 789-795. [CrossRef] [PubMed]

25. Balomenos, D.; Shokri, R.; Daszkiewicz, L.; Vázquez-Mateo, C.; Martínez-A, C. On How Fas Apoptosis-Independent Pathways Drive T Cell Hyperproliferation and Lymphadenopathy in lpr Mice. Front. Immunol. 2017, 8, 237. [CrossRef]

26. Wajant, H. The Fas signaling pathway: More than a paradigm. Science 2002, 296, 1635-1636. [CrossRef]

27. Torvaldson, E.; Kochin, V.; Eriksson, J.E. Phosphorylation of lamins determine their structural properties and signaling functions. Nucleus 2015, 6, 166-171. [CrossRef]

28. Foster, C.R.; Przyborski, S.A.; Wilson, R.G.; Hutchison, C.J. Lamins as cancer biomarkers. Biochem. Soc. Trans. 2010, 38, 297-300. [CrossRef] [PubMed]

29. Koul, H.K.; Pal, M.; Koul, S. Role of p38 MAP Kinase Signal Transduction in Solid Tumors. Genes Cancer 2013, 4, 342-359. [CrossRef]

30. Cross, M.J.; Dixelius, J.; Matsumoto, T.; Claesson-Welsh, L. VEGF-receptor signal transduction. Trends Biochem. Sci. 2003, 28, 488-494. [CrossRef]

31. Hassan, M.H.; Eyzaguirre, E.; Arafa, H.M.; Hamada, F.M.; Salama, S.A.; Al-Hendy, A. Memy I: A novel murine model for uterine leiomyoma using adenovirus-enhanced human fibroid explants in severe combined immune deficiency mice. Am. J. Obstet. Gynecol. 2008, 199, 156.e1. [CrossRef]

32. Kostenko, S.; Johannessen, M.; Moens, U. PKA-induced F-actin rearrangement requires phosphorylation of Hsp27 by the MAPKAP kinase MK5. Cell Signal. 2009, 21, 712-718. [CrossRef]

33. Shiota, M.; Bishop, J.L.; Nip, K.M.; Zardan, A.; Takeuchi, A.; Cordonnier, T.; Beraldi, E.; Bazov, J.; Fazli, L.; Chi, K.; et al. Hsp27 regulates epithelial mesenchymal transition, metastasis, and circulating tumor cells in prostate cancer. Cancer Res. 2013, 73, 3109-3119. [CrossRef]

34. Ura, B.; Scrimin, F.; Arrigoni, G.; Aloisio, M.; Monasta, L.; Ricci, G. Dysregulated chaperones associated with cell proliferation and negative apoptosis regulation in the uterine leiomyoma. Oncol. Lett. 2018, 15, 8005-8010. [CrossRef]

35. Paul, C.; Simon, S.; Gibert, B.; Virot, S.; Manero, F.; Arrigo, A.P. Dynamic processes that reflect anti-apoptotic strategies set up by HspB1 (Hsp27). Exp. Cell Res. 2010, 316, 1535-1552. [CrossRef]

36. Evensen, N.A.; Kuscu, C.; Nguyen, H.L.; Zarrabi, K.; Dufour, A.; Kadam, P.; Hu, Y.J.; Pulkoski-Gross, A.; Bahou, W.F.; Zucker, S.; et al. Unraveling the role of KIAA1199, a novel endoplasmic reticulum protein, in cancer cell migration. J. Natl. Cancer Inst. 2013, 105, 1402-1416. [CrossRef] [PubMed]

37. Ng, D.T.; Watowich, S.S.; Lamb, R.A. Analysis in vivo of GRP78-BiP/substrate interactions and their role in induction of the GRP78-BiP gene. Mol. Biol. Cell 1992, 3, 143-155. [CrossRef]

38. Dutta, A.; Girotra, M.; Merchant, N.; Nair, P.; Dutta, S.K. Evidence of multimeric forms of HSP70 with phosphorylation on serine and tyrosine residues-Implications for roles of HSP70 in detection of GI cancers. Asian Pac. J. Cancer Prev. 2013, 14, 5741-5745. [CrossRef] [PubMed]

39. Lim, Y.P.; Wong, C.Y.; Ooi, L.L.; Druker, B.J.; Epstein, R.J. Selective tyrosine hyperphosphorylation of cytoskeletal and stress proteins in primary human breast cancers: Implications for adjuvant use of kinase-inhibitory drugs. Clin. Cancer Res. 2004, 10, 3980-3987. [CrossRef] 
40. Viitanen, P.V.; Lorimer, G.H.; Seetharam, R.; Gupta, R.S.; Oppenheim, J.; Thomas, J.O.; Cowan, N.J. Mammalian mitochondrial chaperonin 60 functions as a single toroidal ring. J. Biol. Chem. 1992, 267, 695-698.

41. Levy-Rimler, G.; Viitanen, P.; Weiss, C.; Sharkia, R.; Greenberg, A.; Niv, A.; Lustig, A.; Delarea, Y.; Azem, A. The effect of nucleotides and mitochondrial chaperonin 10 on the structure and chaperone activity of mitochondrial chaperonin 60. Eur. J. Biochem. 2001, 268, 3465-3472. [CrossRef] [PubMed]

42. Leung, W.H.; Vong, Q.P.; Lin, W.; Bouck, D.; Wendt, S.; Sullivan, E.; Li, Y.; Bari, R.; Chen, T.; Leung, W. PRL-3 mediates the protein maturation of ULBP2 by regulating the tyrosine phosphorylation of HSP60. J. Immunol. 2015, 194, 2930-2941. [CrossRef]

43. Wang, R.; Sun, P.D. Natural killer cell-mediated shedding of ULBP2. PLoS ONE 2014, 9, e91133. [CrossRef]

44. Kang, S.W.; Chae, H.Z.; Seo, M.S.; Kim, K.; Baines, I.C.; Rhee, S.G. Mammalian peroxiredoxin isoforms can reduce hydrogen peroxide generated in response to growth factors and tumor necrosis factor-alpha. J. Biol. Chem. 1998, 273, 6297-6302. [CrossRef] [PubMed]

45. Lu, W.; Fu, Z.; Wang, H.; Feng, J.; Wei, J.; Guo, J. Peroxiredoxin 2 is upregulated in colorectal cancer and contributes to colorectal cancer cells' survival by protecting cells from oxidative stress. Mol. Cell Biochem. 2014, 387, 261-270. [CrossRef] [PubMed]

46. Qu, D.; Rashidian, J.; Mount, M.P.; Aleyasin, H.; Parsanejad, M.; Lira, A.; Haque, E.; Zhang, Y.; Callaghan, S.; Daigle, M.; et al. Role of Cdk5-mediated phosphorylation of Prx2 in MPTP toxicity and Parkinson's disease. Neuron 2007, 55, 37-52. [CrossRef] [PubMed]

47. Katsogiannou, M.; Andrieu, C.; Rocchi, P. Heat shock protein 27 phosphorylation state is associated with cancer progression. Front. Genet. 2014, 5, 346. [CrossRef] [PubMed]

48. Melling, C.W.; Thorp, D.B.; Milne, K.J.; Noble, E.G. Myocardial Hsp70 phosphorylation and PKC-mediated cardioprotection following exercise. Cell Stress Chaperones 2009, 14, 141-150. [CrossRef]

49. Majumder, P.K.; Mishra, N.C.; Sun, X.; Bharti, A.; Kharbanda, S.; Saxena, S.; Kufe, D. Targeting of protein kinase $C$ delta to mitochondria in the oxidative stress response. Cell Growth Diff. 2001, 12, 465-470.

50. Shushan, A.; Rojansky, N.; Laufer, N.; Klein, B.Y.; Shlomai, Z.; Levitzki, R.; Hartzstark, Z.; Ben-Bassat, H. The AG1478 tyrosine kinase inhibitor is an effective suppressor of leiomyoma cell growth. Hum. Reprod. 2004, 19, 1957-1967. [CrossRef]

51. Shushan, A.; Ben-Bassat, H.; Mishani, E.; Laufer, N.; Klein, B.Y.; Rojansky, N. Inhibition of leiomyoma cell proliferation in vitro by genistein and the protein tyrosine kinase inhibitor TKS050. Fertil. Steril. 2007, 87, 127-135. [CrossRef]

52. Lattuada, D.; Viganó, P.; Mangioni, S.; Sassone, J.; Di Francesco, S.; Vignali, M.; Di Blasio, A.M. Accumulation of retinoid $\mathrm{X}$ receptor-alpha in uterine leiomyomas is associated with a delayed ligand-dependent proteasome-mediated degradation and an alteration of its transcriptional activity. Mol. Endocrinol. 2007, 21, 602-612. [CrossRef] [PubMed]

53. Ayusawa, D.; Kaneda, S.; Itoh, Y.; Yasuda, H.; Murakami, Y.; Sugasawa, K.; Hanaoka, F.; Seno, T. Complementation by a cloned human ubiquitin-activating enzyme E1 of the S-phase-arrested mouse FM3A cell mutant with thermolabile E1. Cell Struct. Funct. 1992, 17, 113-122. [CrossRef] [PubMed]

54. Moudry, P.; Lukas, C.; Macurek, L.; Hanzlikova, H.; Hodny, Z.; Lukas, J.; Bartek, J. Ubiquitin-activating enzyme UBA1 is required for cellular response to DNA damage. Cell Cycle 2012, 11, 1573-1582. [CrossRef] [PubMed]

55. Xu, W.; Lukkarila, J.L.; da Silva, S.R.; Paiva, S.L.; Gunning, P.T.; Schimmer, A.D. Targeting the ubiquitin E1 as a novel anti-cancer strategy. Curr. Pharm. Des. 2013, 19, 3201-3209. [CrossRef]

(C) 2019 by the authors. Licensee MDPI, Basel, Switzerland. This article is an open access article distributed under the terms and conditions of the Creative Commons Attribution (CC BY) license (http://creativecommons.org/licenses/by/4.0/). 